International Journal of Current Microbiology and Applied Sciences

ISSN: 2319-7706 Volume 10 Number 10 (2021)

Journal homepage: http://www.ijcmas.com

\title{
Detection and Molecular Characterization of Orientia tsutsugamushi from Suspected Scrub Typhus Patients in Mizoram, India
}

\author{
Vanramliana $^{1 *}$, Gabriel Rosangkima ${ }^{1}$, Lalnunnemi ${ }^{2}$, Ralte Lalremruata ${ }^{3}$, \\ Christine Vanlalbiakdiki Sailo ${ }^{3}$, Hunropuia ${ }^{1}$, Deborah Lalnghakmawii ${ }^{1}$ \\ and Lalfakzuala Pautu ${ }^{1}$
}

${ }^{1}$ Department of Zoology, Pachhunga University College, Aizawl, Mizoram, 796 005, India

${ }^{2}$ Department of Pathology, ${ }^{3}$ Department of Microbiology, Synod Hospital,

Durtlang, Mizoram - 796 015, India

*Corresponding author

\section{A B S T R A C T}

Keywords

Molecular, serological, nested PCR, Orientia tsutsugamushi, scrub typhus

Article Info

Accepted: 18 September 2021 Available Online: 10 October 2021
Serologic and molecular tests were performed for the diagnosis and to detect $O$. tsutsugamushi genotypes that are circulating in the state of Mizoram, India. Blood samples from scrub typhus-suspected patients were collected from Synod Hospital, Durtlang, Mizoram. Weil-Felix and immunochromatographic test (ICT) were performed from the serum samples. Nested PCR (nPCR) amplification of $47 \mathrm{kDa}$ outer membrane protein antigen gene and $56 \mathrm{kDa}$ type-specific antigen gene were done from the whole blood. 141/177 (79.66\%) and 134/177 (75.7\%) cases showed the presence of antibody against scrub typhus by Weil-Felix and ICT assays respectively. 76/177 (42.93\%) patients showed the presence of $47 \mathrm{kDa}$ OMP antigen gene by nPCR while 55/177 (31.07\%) showed the presence of $56 \mathrm{kDa}$ TSA gene by nPCR. Phylogenetic analysis of $56 \mathrm{kDa}$ TSA gene sequence revealed that Karp-related genotype was the most common genotype in the study area followed by Kato-related genotype. In this study, a high degree of diversity of $O$. tsutsugamushi was observed similar to the observations reported from other parts of India. Nested PCR of 47kDa OMP antigen gene showed higher sensitivity as compared to $\mathrm{nPCR}$ amplification of 56kDa TSA gene suggesting it as the assay of choice for diagnosis of scrub typhus disease.

\section{Introduction}

Scrub typhus is an acute febrile illness. It is caused by the obligate intracellular bacterium Orientia tsutsugamushi and is transmitted to human by the bite of larval stages of thrombiculid mites (Seong et al., 2001). Those, who inhabit regions infested with these vectors, are at high risk of acquiring scrub typhus (Tantibhedhyangkul et al., 2011). It has been reported that scrub typhus disease causes illness in one million people each year, 
with variable mortality rate $(0-70 \%)$ and one billion people are at risk worldwide (Kelly et al., 2009). Scrub typhus is endemic in geographical region known as "tsutsugamushi triangle", which extends from Northern Japan to Eastern Russia in the north, Northern Australia in the south and Pakistan and Afghanistan in the west (Xu et al., 2017). An endemic focus of scrub typhus has also been described in southern Chile (Weitzel et al., 2016). A number of genotypes such as Karp, Gilliam, Kuroki, Kato, Shimokoshi, Kawasaki etc. have been recognized based on the $56 \mathrm{kDa}$ type-specific antigen (TSA), which is an immunodominant outer membrane protein unique to this bacterium. Karp is the most common genotype contributing about $50 \%$ of all scrub typhus cases (Nguyen et al., 2017). Genotypic characterization and detailed understanding of genetic diversity of $O$. tsutsugamushi strains in endemic regions will be essential for the development of rapid diagnostics and vaccines. Outbreaks of scrub typhus have been reported from various parts of North, South and Eastern India (Gurung et al., 2013; Varghese et al., 2006; Bakshi et al., 2007; Kumar et al., 2014). In Mizoram state, India, scrub typhus cases has also been reported from both rural and urban areas (Lalrinkima et al., 2017; Lalmalsawma et al., 2017; Lalthazuali et al., 2020).

However, there has been no report regarding the serotypes and genotypes of $O$. tsutsugamushi from this region. Mizoram is one of the eight states of North-east India, at the extreme end of the Himalayan ranges and lies between $92^{\circ} 15^{\prime}$ and $93^{\circ} 26^{\prime} \mathrm{E}$ longitude and $21^{\circ} 58^{\prime}$ and $24^{\circ} 35^{\prime} \mathrm{N}$ latitude (Rosangkima $e t$ al., 2018). The state has two international borders, Bangladesh in the west and Myanmar in the east. The region is influenced by monsoons, with heavy rainfall during the month of May to September. The average annual rainfall is 254 centimetres. The objective of the present study was to perform serologic and molecular tests for the diagnosis of scrub typhus and to detect $O$. tsutsugamushi serotypes that are circulating in the state of Mizoram, India.

\section{Materials and Methods}

\section{Patient recruitment and sample collection}

A prospective study of acute febrile illness was conducted during July to December, 2020 in Synod Hospital, Durtlang, Mizoram, India, and the study was approved by the Institutional Ethical Committee of Synod Hospital, Durtlang, Mizoram. 177 febrile patients who visited the hospital and 48 nondiseased control samples were included in the study. Non-diseased control samples include healthy participants from outside the hospital without any symptoms of scrub typhus disease. Patients suspected to have rickettsial illness due to the fever persisting for at least 5 days or more were enrolled in the present study. Guardian of the patients between 14 and 18 years of age were given written informed consent to participate. Cases with fever of already known causes such as malaria, typhoid, etc. were excluded in the present study. A thorough clinical history was also investigated which include questions about recent exposure to tick habitats, recent travel, similar illness in close contacts and tick bites. However, absence of these features does not rule out tick-borne illness. $3 \mathrm{ml}$ of venous blood was collected from each patient, $2 \mathrm{ml}$ in ethylene diaminetetra acetic acid (EDTA) and $1 \mathrm{ml}$ in a plain tube. Serum from plain tubes were collected and subjected to Weil-Felix and immunochromatographic test (ICT).

The EDTA blood samples were also subjected to DNA extraction using QIAamp DNA Mini Kit (Qiagen, GmBh, Germany) following the manufacturer's instructions. The extracted genomic DNA was stored at $-20^{\circ} \mathrm{C}$ for use in nested PCR amplification. 


\section{Weil-Felix test}

Serological testing of OXK, OX19 and OX2 antibodies were carried out following standard protocol using PROGEN proteus antigen suspensions obtained from Tulip Diagnostics (P) Ltd., Goa, India. The serum samples were diluted and the titre values of more than 1:80 were considered positive for scrub typhus.

\section{Rapid Diagnostic Test}

InBios rapid test (SD Bioline Tsutsugamushi test, SD Diagnostics, Korea), which is an immunochromatographic strip test (ICT) designed specifically for the qualitative detection of IgM to O. tsutsugamushi (Wahid et al., 2014). It consists of ready-to-use antigen-coated strips and reagents. The test strip was precoated with lines, one for ' $\mathrm{T}$ ' $(O$. tsutsugamushi antibody test line), and one for 'C' (control line). The colour intensity developed on the strip is directly related to the antibody concentration.

\section{Nested PCR amplification of 47kDa OMP antigen gene}

nPCR was performed for the detection of the 47kDa OMP antigen gene using OtsuFR263 and OtsuRP1133 primers. The reaction mixture $(25 \mu \mathrm{l})$ consisted of $12.5 \mu \mathrm{l}$ of $2 \mathrm{X}$ MasterMix (Takara), $0.75 \mu$ l each of primers (10 pmol), $9 \mu$ l of nucleus free water and $2 \mu \mathrm{l}$ of DNA template. PCR reaction cycle included an initial denaturation at $94{ }^{\circ} \mathrm{C}$ for $7 \mathrm{~min}$ followed by denaturation at $94^{\circ} \mathrm{C}$ for $30 \mathrm{sec}$, annealing at $60^{\circ} \mathrm{C}$ for $1.5 \mathrm{~min}$ and extension at $72^{\circ} \mathrm{C}$ for $1 \mathrm{~min}$.

The final extension at $72^{\circ} \mathrm{C}$ takes $7 \mathrm{~min}$. The second cycle of nested PCR was prepared by using $1 \mu 1$ of first cycle nPCR product as template and OtsuFP555 and OtsuRP771 primers producing an amplicon size of $216 \mathrm{bp}$. Other reaction components and PCR cycle conditions were similar with those in the first PCR cycle except the annealing temperature of $56^{\circ} \mathrm{C}$ (Srinivasan et al., 2020). The PCR reaction was carried out using a ProFlex PCR System (Applied Biosystems, life technologies).

\section{Nested PCR amplification of 56kDa TSA gene}

A $56 \mathrm{kDa}$ nested PCR was done in order to minimize the contamination and to get improved-sensitivity. The primers used in nested PCR were as described by Particia et al., 2017 (Table 1) (Patricia et al., 2017).

The first cycle of nested PCR was performed using P34 and P55 primers producing an amplicon size of $1003 \mathrm{bp}$. The reaction mixture $(25 \mu \mathrm{l})$ consisted of $12.5 \mu \mathrm{l}$ of $2 \mathrm{X}$ MasterMix (Takara), $0.75 \mu \mathrm{l}$ each of P34 (10 pmol) and P55 (10 pmol), $9 \mu 1$ of Nucleus free water and $2 \mu 1$ of DNA template.

PCR reaction cycle included an initial denaturation at $94{ }^{\circ} \mathrm{C}$ for $7 \mathrm{~min}$ followed by denaturation at $94^{\circ} \mathrm{C}$ for $30 \mathrm{sec}$, annealing at $60^{\circ} \mathrm{C}$ for $30 \mathrm{sec}$ and extension at $72^{\circ} \mathrm{C}$ for 1 min. The final extension at $72^{\circ} \mathrm{C}$ takes $7 \mathrm{~min}$.

The second cycle of nested PCR was prepared by using $1 \mu 1$ of first cycle nested PCR product as template and $\mathrm{P} 10$ and $\mathrm{P} 11$ primers producing an amplicon size of $483 \mathrm{bp}$. Other reaction components and PCR cycle conditions were similar with those in the first PCR cycle (Teppawar et al., 2019). The PCR reaction was carried out using a ProFlex PCR System (Applied Biosystems, life technologies). The diagnostic assays used in the present study (Weil-Felix, ICT, nPCR of $47 \mathrm{kDa}$ and $56 \mathrm{kDa}$ genes) were assessed for sensitivity and specificity using the MedCalc statistical software program (Belgium). A total of 48 healthy, non-diseased samples were used for specificity assessment. 


\section{DNA sequencing and phylogenetic analysis}

The amplified PCR products of $56 \mathrm{kDa}$ TSA gene of $O$. tsutsugamushi were sequenced by Sanger's dideoxy method (Sanger et al., 1997) on ABI 3730XL automated sequencer (AgriGenome Labs Pvt. Ltd., SmartCity Kochi, Kerala, India). Nucleotide sequences obtained from the present study were deposited in the GenBank data library under accession numbers MW620836 to MW620866. Sequences were edited using BioEdit Sequence alignment editor and subjected to phylogenetic tree construction. A phylogenetic dendrogram of the partial $56 \mathrm{kDa}$ protein genes in the present study as well as those obtained from the GenBank database was constructed by the maximum likelihood method using MEGA7 software (Kumar et al., 2016). Sequence identity among 56kDa TSA genes was calculated by the Sequence Identity and Similarity (SIAS) programme (http://imed.med.ucm.es/Tools/sias.html).

\section{Results and Discussion}

A total of 177 scrub typhus-suspected patients were included in this study. The median age of the patients was 42.5 years (ranging from 15 to 86 years). $141 / 177(79.66 \%)$ cases showed scrub typhus positive by Weil-Felix test, of which $53.1 \%$ were female and $26.5 \%$ were male. Immunochromatographic test showed 134/177 $(75.7 \%)$ scrub typhus positive with $32.7 \%$ female and $42.9 \%$ male. Nested PCR of the $47 \mathrm{kDa}$ OMP antigen gene showed $76 / 177$ $(42.93 \%)$ positive with $20.3 \%$ female and $22.6 \%$ male. Nested PCR of 56kDa TSA gene also showed 55/177 (31.07\%) positive with $16.4 \%$ female and $14.7 \%$ male (Table 2; Figure 1). The common symptoms noted among the patients included fever, vomiting, abdominal pain, myaglia, chills, headache and jaundice. Among the four diagnostic assays used for scrub typhus disease in the present study, Weil-Felix test showed the highest sensitivity of $79.66 \%$ (95\% CI, 72.9 to 85.3 ) but lowest specificity of $87.41 \%$ (95\% CI, 75.5 to 94.7$)$. Nested PCR of $47 \mathrm{kDa}$ OMP antigen gene showed higher sensitivity of $42.94 \%$ (95\% CI, 35.5 to 50.5) as compared to nPCR of 56kDa TSA gene showing sensitivity of $31.07 \%$ (95\% CI, 24.3 to 38.4 ).

Neither $47 \mathrm{kDa}$ nor $56 \mathrm{kDa}$ nPCR showed positive for non-diseased samples, and also the primers used were species-specific primers designed for $O$. tsutsugamushi, thereby, revealing perfect specificity $(100 \%)$ of both assays (Table 3).

The $56 \mathrm{kDa}$ TSA gene products (483 bp) were sequenced for randomly selected 37 positive samples. A phylogenetic tree was constructed for these 37 samples together with 40 reference strains (Figure 2). Phylogenetic and sequence analysis revealed that Karp-like strains predominated. Thirty one samples $(83.7 \%)$ out of 37 samples analyzed in the present study clustered within the Karp-related genotype. Four samples $(10.8 \%)$ clustered within the Kato-related genotype, while only one sample each clustered within the Gilliam and TA763-related genotypes. Karp-related genotypes were phylogenetically differentiated into four clades (clade 1, 2, 3 and 4). Seventeen samples were assigned into clade 1, three samples into clade 2, two samples into clade 3 and nine samples into clade 4 . They were clustered with strains from Taiwan, Korea, Thailand, India, China, Japan and Vietnam. Within the partial $56 \mathrm{kDa}$ TSA gene, Karp-related genotype from different clades showed sequence identity of $89.2 \%$ $99.6 \%$, while the sequence identity between Karp-related and Gilliam genotypes was $62 \%$ - 91\% (Table 4). Scrub typhus is prevalent in Asia-Pacific area especially in rural areas of South-East Asia (Rapmund, 1984). However, it is difficult to diagnose due to its non-specific presentations, and lack of relevant laboratory tests (Sinha et al., 2014). 
In India, scrub typhus has been reported from many states accounting for up to $50 \%$ of undifferentiated febrile illnesses during cooler season (Mathai et al., 2003; Abhilash et al., 2015). Scrub typhus responds well to proper antibiotic treatment. However, delayed diagnosis may cause fatal complications (Silpapojakul et al., 1991). Therefore, a rapid diagnosis of scrub typhus is important to get successful treatment.

Weil-Felix is the oldest test and is easy to perform but lacks sensitivity. Due to low antibody levels during the early stages of infection, serological tests may fail to diagnose scrub typhus (Huber et al., 1012). This may reflects the low sensitivity of WeilFelix test in some cases. However, during the later stages of infection, it showed higher sensitivity as observed in the present study. Therefore, it is recommended that the rapid card test should be interpreted in combination with other diagnostic assays and clinical findings (Wahid et al., 2014). In the present study, Weil-Felix and ICT tests were performed as a screening test followed by nPCR targeting $47 \mathrm{kDa}$ OMP antigen gene and $56 \mathrm{kDa}$ TSA gene as confirmatory tests. The sensitivity (79\%) and specificity (87\%) of Weil-Felix test in the result of present study are slightly higher than the range of sensitivity and specificity given by the manufacturer (70\% each). However, the sensitivity of ICT observed in the present study (75\%) was quite lower than the range given by the manufacturer $(99 \%)$ while, specificity $(93 \%)$ was close to manufacturer range (96\%). PCRbased molecular diagnosis targeting different genes have been used in scrub typhus cases. Although the sensitivity of these molecular methods for detection of the target gene is low, they have a very high specificity of up to $100 \%$. The lower sensitivity of these PCRbased molecular methods reported from earlier studies (Kannan et al., 2020) and in the present study could probably be due to the genetic variability associated with the target genes.

Table.1 Details of primer sets used in the present study.

\begin{tabular}{|c|c|c|c|}
\hline $\begin{array}{c}\text { Gene } \\
\text { detected }\end{array}$ & & Primer details & $\begin{array}{l}\text { Product } \\
\text { size }\end{array}$ \\
\hline \multirow{6}{*}{$\begin{array}{l}47 \mathrm{kDa} \\
\mathrm{nPCR}\end{array}$} & (Cycle 1) & & \multirow{6}{*}{$216 \mathrm{bp}$} \\
\hline & OtsuFP263 (Forward) & 5'-GTGCTAAGAAARGATGATACTTC-3' & \\
\hline & OtsuRP1133 (Reverse) & 5'-ACATTTAACATACCACGACGAAT-3' & \\
\hline & (Cycle 2) & & \\
\hline & OtsuFP555 (Forward) & 5'-TCCTTTCGGTTTAAGAGGAACA-3' & \\
\hline & OtsuRP771 (Reverse) & 5'-GCATTCAACTGCTTCAAGTACA-3' & \\
\hline \multirow{6}{*}{$\begin{array}{l}56 \mathrm{kDa} \\
\mathrm{nPCR}\end{array}$} & (Cycle 1) & & \multirow{6}{*}{$483 \mathrm{bp}$} \\
\hline & P34 (Forward) & 5'-TCAAGCTTATTGCTAGTGCAATGTCTGC-3' & \\
\hline & P55 (Reverse) & 5'-AGGGATCCCTGCTGCTGTGCTTGCTGCG-3' & \\
\hline & (Cycle 2) & & \\
\hline & P10 (Forward) & 5'-GATCAAGCTTCCTCAGCCTACTATAATGCC-3' & \\
\hline & P11 (Reverse) & 5'-CTAGGGATCCCGACAGATGCACTATTAGGC-3' & \\
\hline
\end{tabular}


Table.2 Number of positive by different diagnostic assays per a total of 177 cases.

\begin{tabular}{|l|l|l|l|l|l|l|l|}
\hline \multicolumn{2}{|c|}{ Weil Felix } & \multicolumn{2}{c|}{ ICT } & \multicolumn{2}{c|}{ nPCR (47kDa) } & \multicolumn{2}{c|}{ nPCR (56kDa) } \\
\hline Female & Male & Female & Male & Female & Male & Female & Male \\
\hline 94 & 47 & 58 & 76 & 36 & 40 & 29 & 26 \\
\hline $53.1 \%$ & $26.5 \%$ & $32.7 \%$ & $42.9 \%$ & $20.3 \%$ & $22.6 \%$ & $16.4 \%$ & $14.7 \%$ \\
\hline
\end{tabular}

Table.3 Sensitivity and specificity of different diagnostic assays.

\begin{tabular}{|l|c|c|c|c|}
\hline \multirow{2}{*}{$\begin{array}{c}\text { Diagnostic } \\
\text { assays }\end{array}$} & \multicolumn{2}{c|}{ Percent sensitivity } & \multicolumn{2}{c|}{ Percent specificity } \\
\cline { 2 - 5 } & Value & $95 \%$ CI & Value & $95 \%$ CI \\
\hline Weil Felix & $79.66 \%$ & $72.97 \%$ to $85.33 \%$ & $87.27 \%$ & $75.52 \%$ to $94.73 \%$ \\
\hline ICT & $75.71 \%$ & $68.70 \%$ to $81.83 \%$ & $93.75 \%$ & $82.80 \%$ to $98.69 \%$ \\
\hline $47 \mathrm{kDa}$ nPCR & $42.94 \%$ & $35.54 \%$ to $50.58 \%$ & $100 \%$ & $92.60 \%$ to $100 \%$ \\
\hline $56 \mathrm{kDa}$ nPCR & $31.07 \%$ & $24.34 \%$ to $38.45 \%$ & $100 \%$ & $92.60 \%$ to $100 \%$ \\
\hline
\end{tabular}

Table.4 DNA sequence identity (\%) of partial 56kDa type-specific antigen gene among the present study samples with Karp and Gilliam genotypes.

\begin{tabular}{llllllll}
\hline Strain/sample & Karp & KP18 & KP21 & KP71 & KP33 & NT83 & Gilliam \\
\hline KP18 & 98.9 & & & & & & \\
KP21 & 94.4 & 87.5 & & & & & \\
KP71 & 92.9 & 93.4 & 90.5 & & & & \\
KP33 & 94.7 & 89.2 & 93.4 & 95.8 & & & \\
NT83 & 99.6 & 99.0 & 94.6 & 92.9 & 94.9 & & \\
Gilliam & 90.9 & 66.9 & 76.7 & 72.3 & 77.2 & 76.7 & \\
NT19 & 77.5 & 62.2 & 71.1 & 66.5 & 76.2 & 75.7 & 93.6 \\
\hline
\end{tabular}

Fig.1 Bar diagram showing the percentage positivity of different diagnostic assays on scrub typhus suspected cases.

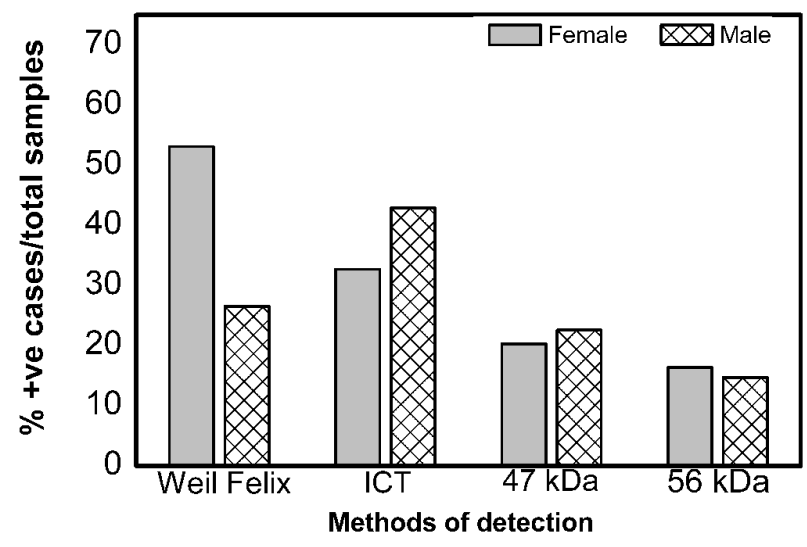


Fig.2 Phylogenetic dendrogram of partial 56kDa TSA gene sequences generated for 77 samples (37 from the present study; 40 from reference strains). The tree was constructed using the neighbour-joining method in MEGA7 software. Tree was statistically supported by bootstrapping with 1000 replicates. Percentage bootstrap support values greater than 75 were shown.

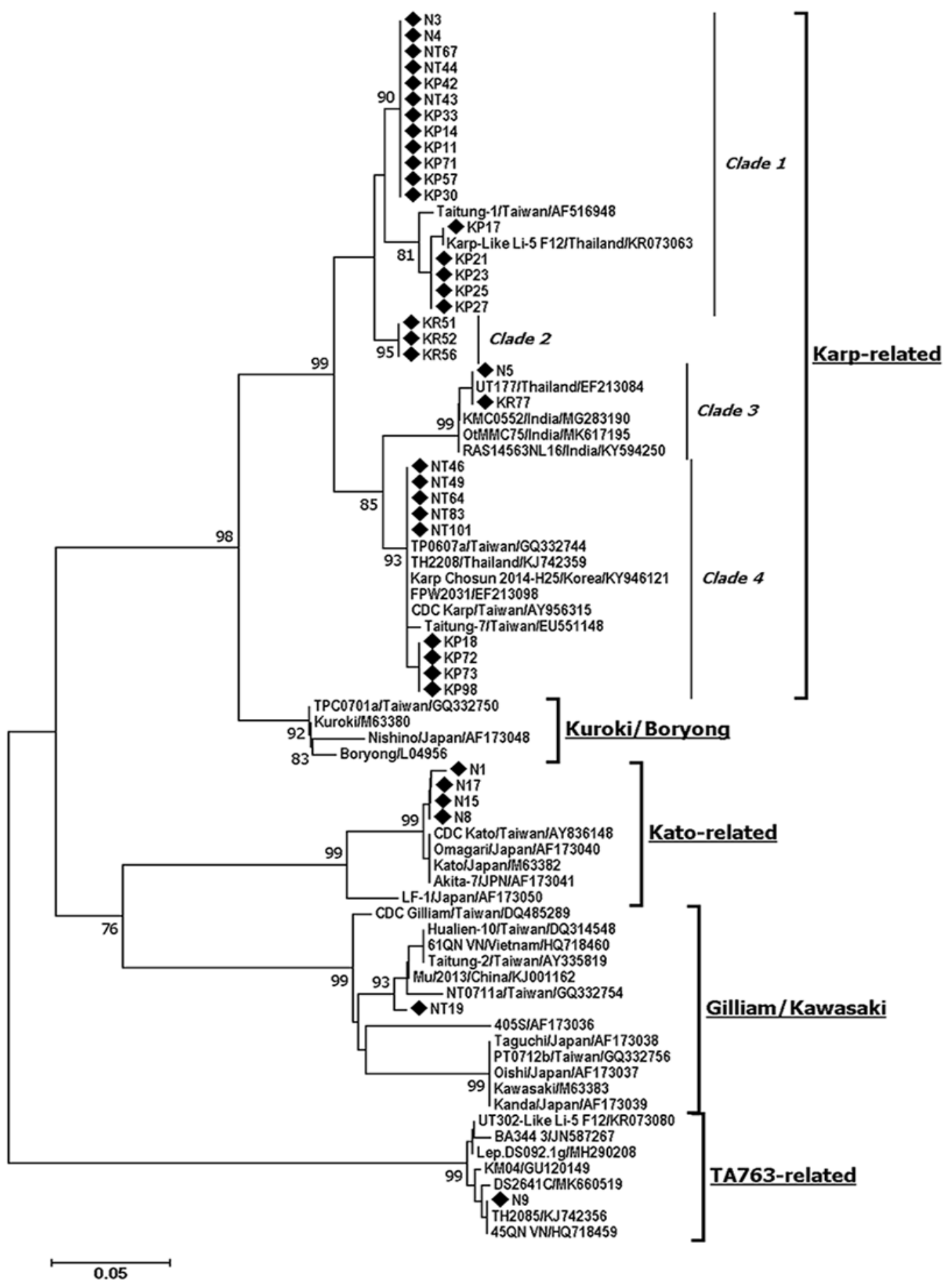


There are a large number of studies documenting the usefulness of $47 \mathrm{kDa}$ for diagnosing scrub typhus (Huber et al., 2012; Kim et al., 2011; Jiang et al., 2004). It is as sensitive as nPCR of other genes. The sensitivity ranges from $40 \%$ to $80 \%$, with specificity of up to $100 \%$ (Peter et al., 2015; Watthanaworawit et al., 2013; Janardhanan et al., 2014). The result of present study presented the diagnostic efficiency of WeilFelix, ICT and nPCR of $47 \mathrm{kDa}$ OMP and $56 \mathrm{kDa}$ TSA genes. Our study revealed highest sensitivity with Weil-Felix assay followed by ICT. However, these two assays exhibited comparatively lower specificity against molecular methods. Nested PCR of $47 \mathrm{kDa}$ OMP gene showed higher sensitivity (42.94\%) as compared to nPCR of $56 \mathrm{kDa}$ TSA gene $(31.07 \%)$. The lower sensitivity of nPCR of $56 \mathrm{kDa}$ TSA gene may be due to low-copy number of target DNA or excess number of host DNA.

More than 20 prototype strains of Orientia tsutsugamushi have been documented so far (Kelly et al., 2009). However, in India, only a few studies have been conducted from the north, south and north-east India regarding the genetic diversity of circulating strains (Varghese et al., 2013; Bora et al., 2018). In the present study we have documented the genetic diversity of $O$. tsutsugamushi in Mizoram state, India. Phylogenetic analysis of $56 \mathrm{kDa}$ TSA gene in the present study revealed the presence of Karp-related, Kato-related, Gilliam-related and TA763-related strains in the study area. Karp-like strains predominated followed by Kato-related strains, while Gilliam and TA763-related strains were detected only on one sample each. In India, the presence of Gilliam and Karp prototypes along with other genotypes closely related to Kuroki, Boryong, Chuto and Kato have been reported (Patricia et al., 2017; Kumar and Beena, 2017). Kato-like strain has also been reported to be very common across the country. In the present study area also Karp and Kato-related strains were comparatively more common than the other strains. The limitation of this study is that the present study was done over a short period of time and included only participants from a single Hospital in the state.

The most prevalent genotype identified in the present study was those in the Karp-related strain. However, considering the higher strain variation across the country, further prospective studies in this area will be required to identify the prevalent strains as well as antigenic variations. As compared to nPCR of $56 \mathrm{kDa}$ TSA gene, nPCR of $47 \mathrm{kDa}$ OMP antigen is more sensitive suggesting it as the assay of choice for diagnosis of scrub typhus disease.

\section{Acknowledgement}

The authors acknowledged the Director, Synod Hospital, Durtlang, Mizoram, for providing the clinical samples and also Head, department of Zoology, Pachhunga University College, Aizawl, Mizoram, for providing laboratory facilities used in this study. The authors are also grateful to Science and Engineering Research Board, New Delhi, for providing financial support under Core Research Grant (Biomedical and Health Sciences) (CRG/2019/003016/BHS; Dated: 07-Feb-2020).

\section{References}

Abhilash, K. P., Gunasekaran, K., Mitra, S., Patole, S., Sathyendra, S., Jasmine, S. et al., 2015. Scrub typhus meningitis: An under-recognized cause of aseptic meningitis in India. Neurol. India. 63: 209214.

Bakshi, D., Singhal, P., Mahajan, S. K., Subramaniam, P., Tuteja, U., Batra, H. V. 2007. Development of a real-time PCR assay for the diagnosis of scrub typhus cases 
in India and evidence of the prevalence of new genotype of $O$. tsutsugamushi. Acta Trop. 104: 63-71.

Bora, T., Khan, S. A., Jampa, L., Laskar, B. 2018. Genetic diversity of Orientia tsutsugamushi strains circulating in Northeast India. Trans. R. Soc. Trop. Med. Hyg. 112: 22-30.

Gurung, S., Pradhan, J., Bhutia, P. Y. 2013. Outbreak of scrub typhus in the North East Himalayan region-Sikkim: an emerging threat. Indian J. Med. Microbiol. 31: 72-74.

Huber, E., Ji, D., Howell, L., Zhang, Z., Chen, H. W., Ching, W. M. et al., 2012. Loopmediated isothermal amplification assay targeting the 47-Kda gene of Orientia tsutsugamushi: A rapid and sensitive alternation to real-time PCR. J. Med. Microbiol. Diagn. 1(4): 1000112.

Janardhanan, J., Trowbridge, P., Varghese, G. M. 2014. Diagnosis of scrub typhus. Expert. Rev. Anti Infect. Ther. 12: 1533-5540.

Jiang, J., Chan, T. C., Temenak, J. J., Dasch, G. A., Ching, W. M., Richards, A. L. 2004. Development of a quantitative real-time polymerase chain reaction assay specific for Orientia tsutsugamushi. Am. J. Trop. Med. Hyg. 70: 351-356.

Kannan, K., John, R., Kundu, D., Dayanand, D., Abhilash, K. P. P., Mathuram, A. J. et al., 2020. Performance of molecular and serologic tests for the diagnosis of scrub typhus. PLoS Negl. Trop. Dis. 14(11): e0008747.

Kelly, D. J., Fuerst, P. A., Ching, W. M., Richards, A. L. 2009. Scrub typhus: the geographic distribution of phenotypic and genotypic variants of Orientia tsutsugamushi. Clin. Infect. Dis. 48(Suppl. 3): S203-230.

Kim, D. M., Park, G., Kim, H. S., Lee, J. Y., Neupane, G. P., Graves, S. et al., 2011. Comparison of conventional, nested, and real-time quantitative PCR for diagnosis of scrub typhus. J. Clin. Microbiol. 49: 607612.

Kumar, G. V., Beena, P. M. 2017. Molecular characterization of Orientia tsutsugamushi in domestic rodents in Kolar Region, Karnataka. Asian J. Epidemiol. 10(3): 123127.

Kumar, S., Stecher, G., Tamura, K. 2016.
MEGA7: Molecular evolutionary genetics analysis version 7.0 for bigger datasets. Mol. Biol. Evol. 33: 1870-1874.

Kumar, V., Kumar, V., Yadav, A. K., Iyengar, S., Bhalla, A., Sharma, N. et al.,., 2014. Scrub typhus is an under-recognized cause of acute febrile illness with acute kidney injury in India. PLoS Negl. Trop. Dis. 8: e2605.

Lalmalsawma, P., Pautu, L., Lalremsiama, N. 2017. Scenario of scrub typhus disease in Mizoram, Northeast India. Int. J. Curr. Adv. Res. 6(10): 6341-6344.

Lalrinkima, H., Lalremruata, R., Lalchhandama, C., Khiangte, L., Siamthara, F. H., Lalnunpuia, C. et al., 2017. Scrub typhus in Mizoram, India. J. Vect. Borne. Dis. 54: 369-371.

Lalthazuali, Sharma, A. K., Thomas, T. G., Bhan, S., Bhadauriya, A. S., Ramteke, P. U. et al., 2020. Entomological survey of vectors of scrub typhus in Haulawng, Lunglei district, Mioram, India. J. Communicable Dis. 52(2): 69-73.

Mathai, E., Rolain, J. M., Verghese, G. M., Abraham, O. C., Mathai, D., Mathai, M. et al., 2003. Outbreak of scrub typhus in Southern India during the cooler months. Ann. N. Y. Acad. Sci. 990: 359-364.

Nguyen, H. L. K., Pham, H. T. T., Nguyen, T. V., Hoang, P. V., Le, M. T. Q., Takemura, T. et al., 2017. The genotypes of Orientia tsutsugamushi, identified in scrub typhus patients in northern Vietnam. Trans. R. Soc. Trop. Med. Hyg. 111: 137-139.

Patricia, A. K., Hoti, S. L., Reba, K., Jambulingam, P., Yasin, N., Shashikala, N. et al., 2017. Occurrence of Orientia tsutsugamushi genotypes in areas of Union Territory of Puducherry and Tamil Nadu state, India. J. Infect. Dis. and Pathol. 2: 124.

Patricia, K. A., Hhoti, S. L., Kanungo, R., Jambulingam, P., Shashikala, N., Naik, A. C. 2017. Improving the Diagnosis of Scrub Typhus by Combining groEL Based Polymerase Chain Reaction and IgM ELISA. J. Clin. and Diagnostic Res. 11(8): DC27-DC31.

Peter, J. V., Sudarsan, T. I., Prakash, J. A., Varghese, G. M. 2015. Severe scrub typhus infection: Clinical features, diagnostic 
challenges and management. World J. Crit. Care Med. 4: 244-250.

Rapmund, G. 1984. Rickettsial diseases of the Far East: new perspectives. J. Infect. Dis. 149: 330-338.

Rosangkima, G., Vanramliana, Lalthanzara, H., Lalringngheti, Lalramnghaki, H. C. 2018. Isolation and molecular characterization of ginger soft rot pathogenic fungi in Aizawl district of Mizoram, India. Sci. Vis. 18(4): 111-119.

Sanger, F., Nicklen, S., Coulson, A. R. 1997. DNA sequencing with chainterminating inhibitors. Proc. Natl. Acad. Sci. USA. 74: 5463-5467.

Seong, S. Y., Choi, M. S., Kim, I. S. 2001. Orientia tsutsugamushi infection: overview and immune responses. Microbe. Infect. 3: $11-21$.

Silpapojakul, K., Chupuppakarn, S., Yuthasompob, S., Varachit, B., Chaipak, D., Borkerd, T. et al., 1991. Scrub and murine typhus in children with obscure fever in the tropics. Pediatr. Infect. Dis. J. 10: 200-203.

Sinha, P., Gupta, S., Dawra, R., Rijhawan, P. 2014. Recent outbreak of scrub typhus in north Western part of India. Indian J. Med. Microbiol. 32: 247-250.

Srinivasan, S., Kalaimani, S., Prakash, J. A. J., Menon, T. 2020. Comparison of nested polymerase chain reaction and real-time polymerase chain reaction targeting $47 \mathrm{kDa}$ gene for the diagnosis of scrub typhus. Indian J. Med. Microbiol. 37(1): 50-53.

Tantibhedhyangkul, W., Prachason, T., Waywa, D., El Filali, A., Ghigo, E., Thongnoppakhun, W. et al., 2011. Orientia tsutsugamushi stimulates an original gene expression program in monocytes: relationship with gene expression in patients with scrub typhus. PLoS Negl. Trop. Dis. 5: e1028.
Teppawar, R., Patil, A., Chaudhari, S., Shinde, S., Kolte, S., Bhoyar, A. et al., 2019. Zoonotic importance of rodents and their vectors in relation to perpetuation of scrub typhus in population. J. Entomol. and Zool. Studies. 7(2): 60-64.

Varghese, G. M., Abraham, O. C., Mathai, D., Thomas, K., Aaron, R., Kavitha, M. L. et al., 2006. Scrub typhus among hospitalised patients with febrile illness in South India: magnitude and clinical predictors. J. Infect. 52: 56-60.

Varghese, G. M., Janardhanan, J., Trowbridge, P., Peter, J. V., Prakash, J. A., Sathyendra, S. et al., 2013. Scrub typhus in South India: clinical and laboratory manifestations, genetic variability, and outcome. Int. J. Infect. Dis. 17(11): 981-987.

Wahid, A., Meena, S. R., Saluja, M., Jain, G., Pahadia, M., Puneeth, U. M. 2014. Epidemic of scrub typhus in Haroti region of Rajasthan. Indian Med. Gaz. 435-440.

Watthanaworawit, W., Turner, P., Turner, C., Tanganuchitcharnchai, A., Richards, A. L., Bourzac, K. M. et al., 2013. A prospective evaluation of real-time PCR assays for the detection of Orientia tsutsugamushi and Rickettsia spp. for early diagnosis of rickettsial infections during the acute phase of undifferentiated febrile illness. Am. J. Trop. Med. Hyg. 89: 308-310.

Weitzel, T., Dittrich, S., López, J., Phuklia, W., Martinez-Valdebenito, C., Velásquez, K. et al., 2016. Endemic scrub typhus in South America. N. Engl. J. Med. 375: 954-961.

Xu, G., Walker, D. H., Jupiter, D., Melby, P. C., Arcari, C. M. 2017. A review of the global epidemiology of scrub typhus. PLoS Negl. Trop. Dis. 11: e0006062.

\section{How to cite this article:}

Vanramliana, Gabriel Rosangkima, Lalnunnemi, Ralte Lalremruata, Christine Vanlalbiakdiki Sailo, Hunropuia, Deborah Lalnghakmawii and Lalfakzuala Pautu. 2021. Detection and Molecular Characterization of Orientia tsutsugamushi from Suspected Scrub Typhus Patients in Mizoram, India. Int.J.Curr.Microbiol.App.Sci. 10(10): 514-523.

doi: https://doi.org/10.20546/ijcmas.2021.1010.061 